\title{
Lactobacillus acidophilus/Estriol Vaginal Tablet
}

National Cancer Institute

\section{Source}

National Cancer Institute. Lactobacillus acidophilus/Estrio/ Vaginal Tablet. NCI Thesaurus. Code C97257.

A vaginal tablet containing a low dose of the estrogen hormone estriol and lyophilized lactobacillus acidophilus, with hormone replacement and vag inal flora restoring activity. Upon vaginal application, estriol may restore estrogen levels locally and may relieve symptoms caused by estrogen deficiency; the Lactobacillus acidophilus may be able to restore the vaginal Lactobacillus flora. 